\title{
Endoscopic ultrasonography with fine-needle aspiration: present situation and indications
}

\author{
J. J. Vila Costas \\ Service of Digestive Diseases. Hospital de Navarra. Pamplona. Navarra, Spain
}

\begin{abstract}
Endoscopic ultrasonography with fine-needle aspiration is a safe technique that allows the collection of tissue samples for histological diagnosis, as well as therapeutic maneuvers. It has better diagnostic accuracy versus other exploration techniques used for the staging of neoplasms in the gastrointestinal tract as well as in other organs. The risk for complications is extremely low, and the procedure has been shown to be cost-effective in many studies. In this paper we attempt to review the main present indications of endoscopic ultrasonography with fine-needle aspiration.
\end{abstract}

Key words: Endosonography. Fine-needle biopsy. Diagnostic imaging. Neoplasm staging.

Vila Costas JJ. Endoscopic ultrasonography with fine-needle aspiration: present situation and indications. Rev Esp Enferm Dig 2005; 97: 899-906.

\section{INTRODUCTION}

Endoscopic ultrasonography or echoendoscopy integrates endoscopic examination and ultrasound imaging in one single piece of equipment. Three endosonographic examination systems are primarily available (1):

-Radial system: using a mechanic rotary or electronic device, it obtains $360^{\circ}$ ultrasonographic images perpendicular to the transducer's axis, with frequencies available including 5, 7.5, 12, and $20 \mathrm{MHz}$. It allows neither

Recibido: 03-01-05.

Aceptado: 10-05-05.

Correspondencia: Juan J. Vila Costas. Servicio de Aparato Digestivo. Hospital de Navarra. C/ Irunlarrea, 3. 31008 Pamplona. e-mail: xoanxose@ hotmail.com color Doppler studies, nor deep tissue sampling for histological examination. From this point on, this technique will be referred to as EUS.

- Sectorial system: it allows ultrasonographic examination using $100^{\circ}$ longitudinal sections, which are obtained through an oblique-beam electronic transducer with 5 and $7.5 \mathrm{MHz}$ frequencies. It allows both qualitative and quantitative color Doppler vascular examinations, deep tissue sampling using fine-needle $(22 \mathrm{G})$ aspiration (FNA) or biopsy collection with a $19 \mathrm{G}$ tru-cut, and drainage using 6 to $10 \mathrm{~F}$ protheses. From this point on, this technique will be referred to as EUS-FNA.

-Ultrasound miniprobes: they are introduced with the help of a wire guide or through a conventional endoscope's working channel. They may be either mechanic or electronic, and may offer radial or linear images.

Regarding their image acquisition system, echoendoscopy devices may be classified as follows:

- Mechanic: having a rotary transducer system, their drawback is a lower image resolution. They are only used for radial echoendoscopy.

-Electronic: available both as sectorial and radial systems since year 2000. They offer images with higher quality and resolution when compared to mechanic devices (2).

The goal of this paper is to review the current indications of EUS-FNA, and its potential work fields in the future.

EUS is relatively recent technique that has become the modality offering greater accuracy in the diagnosis of benign conditions and the diagnosis and staging of malignancies in the upper gastrointestinal tract, rectum, mediastinum, retroperitoneum, pancreas, adrenal glands, and bile ducts.

The goal when staging any cancer is to establish the operability of the primary tumor in order to avoid pointless surgical procedures. This allows a better scheduling of treatment, and a better selection of patients eligible for 
surgery, be it with curative or palliative intent. EUS-FNA completes and complements EUS, as it allows -as previously discussed- color Doppler explorations and deep adenopathy or neighboring organ puncturing for histology. It provides more accurate staging for gastrointestinal tract, pancreas, lung, and other neoplasms, as we shall discuss below:

-Esophagus: here EUS is used for tumor staging, and to examine submucosal lesions and esophageal duplication cysts. For tumors, EUS has the highest diagnostic accuracy for $\mathrm{T}$ and $\mathrm{N}$ staging, with a precision of $85 \%$ for $\mathrm{T}$ and $79 \%$ for N. In adenopathies suspected to correspond to lymphatic metastases from primary esophageal tumors, FNA -which may be attempted with EUS-FNAfurther improves $\mathrm{N}$-staging specificity, which may reach $100 \%$. In addition, EUS-FNA allows in selected patients the collection of pleural or peritoneal fluid to confirm their malignant involvement, or the collection of liver tissue when metastatic lesions are identified.

In a study performed to assess the impact of EUS-FNA in the management of patients with esophageal cancer it was seen that EUS-FNA increased diagnostic accuracy from 83 to $89 \%$. The number of surgical procedures was thus decreased when patients with non-resectable tumors were appropriately classified as not eligible for surgery (3). This way EUS-FNA was also shown to be the most cost-effective technique for the staging and therapeutic triage of patients with esophageal cancer. With this same regard, another study showed that positron-emission tomography (PET) in association with EUS-FNA was the best approach to the appropriate staging of esophageal cancer. This combination is more effective, and also more expensive, than that of CT and EUS-FNA (4). Choosing between either combination should depend on the financial and technical resources available, and in both of them EUS-FNA obviously plays a crucial role and may not be substituted for by EUS.

-Stomach and upper gastrointestinal tract: EUSFNA is the technique offering the highest diagnostic yield in the staging of gastric tumors, with a precision of $80 \%$ at assessing $\mathrm{T}$ stage and of $77 \%$ at examining $\mathrm{N}$ stage, partly due to its potential for sample collection regarding the cytologic study of suspisious adenopathies.

On the other hand, EUS plays a relevant role in the study of submucosal tumors, both at the gastric and esophageal level. It allows the wall layer from which the lesion derives to be identified in virtually $100 \%$ of cases. In addition, EUS differentiates between true submucosal lesions and extrinsic compressions with a sensitivity of $92 \%$ and a specificity of $100 \%$. However, EUS sensitivity and specificity to distinguish benign lesions from malignancies in the assessment of such submucosal lesions is only 64 and $80 \%$, respectively $(5,6)$. In this respect, the recognition of lesions corresponding to leiomyomas is important, as these may be monitored with EUS when they are small, whereas other submucosal lesions such as leiomyosarcomas or GIST must be surgically resected.
Such differential diagnosis may only be reached based on the histological and immunohistochemical features of the lesion, and thus tumor sampling is essential. In these tumors the collection of adequate material for histological evaluation is impossible using conventional endoscopy, but not so using EUS-FNA. Thus, in a study performed in Japan EUS-FNA obtained a useful sample from all patients studied, and an immunohistochemical diagnosis of GIST was reached without recourse to surgery (7).

Another condition where EUS -and particularly EUSFNA- proves very useful are intestinal duplication cysts. In a recent series CT was seen to provide wrong diagnoses in $70 \%$ of these patients, whereas EUS-FNA correctly diagnosed all patients by allowing cyst puncturing and the subsequent analysis of intracystic fluid. Diagnoses were thus confirmed and surgery could be avoided (8), which resulted in economic savings and lesser aggressiveness for patients.

-Mediastinum: EUS-FNA is very useful in the study of mediastinal lesions. In the study of mediastinal adenopathies EUS has a diagnostic accuracy superior to that of CT or PET, and EUS-FNA specificity further increases that of EUS -from 71 to $100 \%$ - in the recognition of malignant adenopathies. Thus, mediastinoscopy and thoracoscopy may be avoided in these patients, as adenopathy malignity must be histologically confirmed before surgery exclusion.

EUS sensitivity in the screening of mediastinal involvement from lung cancer -which suggests an advanced stage not eligible for surgery- is $73 \%$, and specificity when using EUS-FNA is $100 \%$. In patients with lung cancer and mediastinal adenopathies the use of EUS is known to avoid surgery, which would be unnecessary in approximately $1 / 3$ of patients (9).

In a similar study, the use of EUS-FNA allowed a $40 \%$ decrease in staging costs per patient when FNA demonstrated the presence of mediastinal adenopathies, thus saving a relevant number of mediastinoscopies and exploratory thoracotomies (10). The diagnostic accuracy and cost-effectiveness of EUS-FNA, CT, PET, and mediastinoscopy have been compared for the assessment of the mediastinum in patients with lung cancer. EUS-FNA and PET were seen to offer a similar sensitivity and negative predictive value for the detection of metastatic adenopathies: sensitivity was 63 vs. $68 \%$, and negative predictive value was 68 vs. $64 \%$, respectively. As tissue collection was possible with EUS-FNA, the latter had a superior positive predictive value, with a specificity of 100 versus $72 \%$ for PET. CT sensitivity was only $43 \%$. The cost-effectiveness analysis showed that EUS-FNA was clearly the most cost-effective modality (11). Therefore, it is suggested that, following a CT scan, EUS-FNA be the modality of choice for the identification of patients with non-operable lung cancer.

In another series where 86 patients with mediastinal adenopathies in the absence of gastrointestinal tumor were studied with EUS-FNA, the latter technique's sensi- 
tivity, specificity, diagnostic accuracy, negative predictive value, and positive predictive value to tell benign from malignant mediastinal adenopathies were 96, 100, 98, 94 and $100 \%$, respectively. EUS diagnostic accuracy was $79 \%$, as eas that of CT (versus $98 \%$ for EUS-FNA). EUS-FNA-derived results led to surgery avoidance in $80 \%$ of studied patients (12), again with resulting savings in costs and morbidity.

Another research where the utility of EUS-FNA was evaluated in the study of mediastinal adenopathies showed that using this technique significantly impacted on patient management, changing therapeutic plans in view of the results obtained with this technique in $38 \%$ of patients (13).

EUS-FNA is also useful in the study of mediastinitis. In a study performed in ICU-admitted patients EUS-FNA allowed not only to confirm the diagnosis of mediastinitis, but also the identification of the causing agent upon the provision of material for analysis and culture (3).

-Colon and rectum: at the rectal level EUS is particularly indicated for rectal cancer staging, fecal incontinence studies, abscesses, and perirectal fistula. Regarding rectal cancer, appropriate staging allows a selection of those patients who will benefit from oncologic neoadjuvant therapy (T3 or higher, and/or N+ tumors). The use of neoadjuvant therapy in these advanced rectal tumors has been seen to bring about better disease control, with improved prognosis and survival in these patients (14). Accuracy in the assessment of $\mathrm{T}$ stage is around $80-92 \%$, while it is $77 \%$ regarding N staging. Sensitivity for N staging is $71 \%$, and specificity is $79 \%$.

In a study to establish the impact of EUS-FNA on the staging and management of rectal cancer, and to compare the staging accuracy of CT, EUS, and EUS-FNA, the latter was seen to have an accuracy of $92 \%$ for $\mathrm{N}$ staging, superior to that of EUS (85\%) and CT (68\%). Thus, when considering data obtained with EUS versus the initial CT scan the therapeutic management was changed in $38 \%$ of patients, as adenopathies not previously detected by CT were identified. When EUS-FNA was used in patients with N1 stage, adenopathy puncturing showed a benign nature in $19 \%$ of patients, and lymph nodes regressed to an N0 stage with the resulting therapy change. In this same study EUS-FNA allowed the diagnosis of cancer recurrence with $100 \%$ diagnostic accuracy (15).

-Pancreas and bile ducts: from the outset EUS demonstrated its ability to collect the best information from the liver parenchyma, its duct system, and its relation to neighboring structures, as well as the presence of adenopathies. In addition, EUS-FNA allows the Doppler study of vascular structures, and the puncturing and sampling of pancreatic lesions and lymph nodes in order to complete bile-duct and pancreatic neoplasm staging. When this technique is not available, the collection of material for histology is performed transcutaneously under radiographic control, or by using a surgical procedure. EUS-FNA sensitivity, specificity, positive predic- tive value, and negative predictive value in the tissular diagnosis of solid pancreatic lesions are 94.7, 100, 100, and $85.2 \%$, respectively, values that no other diagnostic modality has ever reached (16). FNA sensitivity under radiographic control has been reported around $80 \%$ $(17,18)$. In the study of pancreatic tumors, EUS-FNA has been seen to eventually contraindicate surgery in $41 \%$ of cases, avoided other diagnostic tests in $57 \%$, and modified medical action regarding treatment in $68 \%$, which has resulted in financial savings (19). This applies not only to solid lesions but also to pancreatic cystic lesions where EUS cannot reliably differentiate benign from malignant illness (20), whereas EUS-FNA provides a histological diagnosis in $95.2 \%$ of these lesions (21). In addition, EUS-FNA allows the management of many cystic lesions, thus avoiding surgical procedures in these patients (22).

EUS is highly useful in the study of bile-duct lesions (23) but EUS-FNA is more cost-effective, as it allows the study not only of bile ducts but also a better staging of cholangiocarcinomas. A histological confirmation of malignity is to be preferred in these patients before any attempts at curative surgery are made. Usually, histological material is obtained by ERCP or via the transcutaneous route, but diagnostic yield with these methods may be only $20 \%$ or even smaller for small-sized or complexstenosis tumors. Thus, many patients undergo radical surgery without a histologically established diagnosis of cholangiocarcinoma. The percentage of patients with benign illnesses inappropriately undergoing radical surgery is around $15 \%$. Forty-four patients with suspected hiliar cholangiocarcinoma following CT, ERCP, and EUS, with negative cytological sampling during ERCP, and thus eligible for radical surgery were examined with EUS-FNA before surgical decision making. The material thus obtained allowed a correct diagnosis in 43 patients. By studying such material 12 patients were seen to really have benign conditions, and 5 had hiliar compression by metastatic adenopathies originating in other tumors. Inappropriate surgical procedures were thus prevented in these 17 patients, with the resulting cost savings (23).

On the other hand, EUS-FNA is useful and safe for the collection of samples from gallbladder masses (24).

-Pelvic masses: EUS-FNA is also used for the study of pelvic tumors, including the collection of material for histological analysis. As for other sites, alternative tissue sampling modalities include transcutaneous puncturing under radiographic control and surgery. When compared to the former, EUS-FNA is clearly advantageous, as it allows the collection of valid samples in all cases (25), whereas this was not the case in $10.7 \%$ of patients with CT (26). EUS-FNA sensitivity, specificity, negative predictive value, and positive predictive value were 88,100 , 100 , and $89 \%$, respectively.

-Miscellanea: EUS-FNA is also highly useful in the diagnosis of the following conditions:

- Functioning neuroendocrine tumors: EUS-FNA is a 
highly accurate technique for the visualization of functioning neuroendocrine tumors inconspicuous on CT scans, and the identification of patients with multiple lesions. In addition, it allows highly accurate cytological confirmations in these patients (27).

- Hepatocarcinomas and other liver tumors: besides its potential to puncture hepatocarcinomas and liver metastases (28), EUS-FNA allows the diagnosis of these tumors when in association with portal thrombi by puncturing these (29). Given the possibility of biopsy collection using a 19G tru-cut, EUS-FNA has been used for liver biopsies in patients with coagulopathy (30).

- Head and neck tumors: playing the same role as in lung cancer staging, EUS-FNA has been successfully used for head and neck cancers, and appropriately changed diagnostic and therapeutic management for $87.5 \%$ of patients in one series (31).

- Cholangiopancreatography guidance: EUS-FNA has been used to access bile ducts by puncturing through the papilla, with the potential of subsequently placing a bile drain. This should be used in patients where bile ducts cannot be accessed using ERCP, thus avoiding transparietohepatic cholangiography as well as its associated complications and costs (32).

- Celiac plexus infiltration: EUS-FNA may be used for celiac plexus infiltration in the management of difficult-to-control chronic pain, and in chronic pancreatitis and pancreas cancer patients. It is a very useful technique that reduces pain severity and opioid doses in these patients (32). It also avoids the risks of transcutaneous infiltration under radiographic control, as in series reporting infiltration using EUS-FNA virtually no complications are described (33-35). In a study comparing the efficacy of celiac plexus block under CT or EUS-FNA, EUS-FNA was seen to allow pain control and a reduction of analgesic medication in twice as many patients versus CT, and also was more cost-effective (33). These data were confirmed by other ad hoc studies $(34,35)$.

- Intratumoral substance injection: useful for liver tumor alcoholization, anti-tumor gene therapy, and radiofrequency administration (32).

- Other therapeutic uses: botulinum toxin injection in achalasia, and management of esophageal varices and bleeding (32).

To conclude, EUS-FNA is clearly a safe technique with a high diagnostic accuracy that is unmatched by other modalities in the staging of various gastrointestinal tract and neighboring organ tumors. It allows numerous therapeutic maneuvers, and has an extremely low complications rate; its role is even reinforced by cost-effectiveness analyses.

\section{REFERENCES}

1. Varas Lorenzo MJ. Equipos, técnica e indicaciones en ecoendoscopia. En: Ultrasonografía endoscópica. Tomo I. Ed.: José Souto Ruzo. Barcelona: Editorial Glosa, 2002.
2. Niwa K, Hirooka Y, Niwa Y, Itoh A, Ohmiya N, Hashimoto S, et al. Comparison of image quality between electronic and mechanical radial scanning echoendoscopes in pancretic diseases. J Gastroenterol Hepatol 2004; 19: 454-9.

3. Chang KJ, Soetikno RM, Bastas D, Tu C, Nguyen PT. Impact of endoscopic ultrasound combined with fine-needle aspiration biopsy in the management of esophageal cancer. Endoscopy 2003; 35: 962-6.

4. Das A, Chak A. Endoscopic ultrasonography. Endoscopy 2004; 36 : $17-22$.

5. Rosch T, Kapfer B, Will U, Baronius W, Strobel M, Lorenz R, et al. Accuracy of endoscopic ultrasonography in upper gastrointestinal submucosal lesions: a prospective multicenter study. Scand J Gastroenterol 2002; 37: 856-62.

6. Stelow EB, Stanley MW, Mallery S, Lai R, Linzie BM, Bardales RH. Endoscopic ultrasound-guided fine-needle aspiration findings of gastrointestinal leiomiomas and gastrointestinal stromal tumors. Am J Clin Pathol 2003; 119: 703-8.

7. Kinoshita K, Isozaki K, Tsutsui S, Kitamura S, Hiraoka S, Watabe K, et al. Endoscopic ultrasonography-guided fine needle aspiration biopsy in follow-up patients with gastrointestinal stromal tumours. Eur J Gastroenterol Hepatol 2003; 15: 1189-93.

8. Eloubeidi MA, Cohn M, Cerfolio RJ, Chhieng DC, Jhala N, Jhala D, et al. Endoscopic ultrasound-guided fine-needle aspiration in the diagnosis of foregut duplication cysts: the value of demonstrating detached ciliary tufts in cyst fluid. Cancer 2004; 102: 253-8.

9. Bruno KJ. Endoscopic ultrasonography. Endoscopy 2003; 35: 92032.

10. Kramer H, van Putten JW, Post WJ, van Dullemen HM, Bongaerts AH, Pruim J, et al. Oesophageal endoscopic ultrasound with fine needle aspiration improves and simplifies the staging of lung cancer. Thorax 2004; 59: 596-601.

11. Fritscher-Ravens A, et al. Endoscopic ultrasonography-guided fineneedle aspiration compared to positron emission tomography and computed tomography for determining operability of lung cancer. Am J Respir Crit Care Med 2003; 168: 1293-7.

12. Wiersema MJ, Vázquez-Sequeiros E, Wiersema LM. Evaluation of mediastinal lymphadenopathy with endoscopic US-guided fine-needle aspiration biopsy. Radiology 2001; 219: 252-7.

13. Hernandez LV, Mishra G, George S, Bhutani MS. A descriptive analysis of EUS-FNA for mediastinal lymphadenopathy: an emphasis on clinical impact and false negative results. Am J Gastroenterol 2004; 99: 249-54.

14. Frykholm GJ, Glimelius B. Preoperative or postoperative irradiation in adenocarcinoma of the rectum: final treatment results of a randomized trial and an evaluation of late secondary effects. Dis Colon Rectum 1993; 36: 564-72.

15. Shami VM, Parmar KS, Waxman I. Clinical impact of endoscopic ultrasound and endoscopic ultrasound-guided fine-needle aspiration in the management of rectal carcinoma. Dis Colon Rectum 2004; 47: 59-65.

16. Eloubeidi MA, Jhala D, Chhieng DC, Chen VE, Eltoum I, Vickers S, et al. Yield of endoscopic ultrasound-guided fine-needle aspiration biopsy in patients with suspected pancreatic carcinoma. Cancer 2003; 99: 285-92.

17. Pinto MM, Ávila NA, Criscuolo EM. Fine needle aspiration of the pancreas. A five-year experience. Acta Cytol 1988; 32: 39-42.

18. Bret PM, Nicolet V, Labadie M. percutaneous fine-needle aspiration biopsy of the pancreas. Diagn Cytopathol 1986; 2: 221-7.

19. Lambert $\mathrm{R}$, et al. International workshop on the clinical impact of endoscopic ultrasound in gastroenterology. Endoscopy 2000; 32: 549-84.

20. Ahmad NA, Kochman ML, Lewis JD, Ginsberg GG. Can EUS alone differentiate between malignant and benign cystic lesions of the pancreas? Am J Gastroenterol 2001; 96: 3295-300.

21. Hernández LV, Mishra G, Forsmark C, Draganov PV, Petersen JM, Hochwald SN, et al. Role of endoscopic ultrasound and EUS-guided fine-needle aspiration in the diagnosis and treatment of cystic lesions of the pancreas. Pancreas 2002; 25: 222-8.

22. De Palma GD, Galloro G, Puzziello A, Masone S, Persico G. Endoscopic drainage of pancreatic pseudocysts: a long-term follow-up study of 49 patients. Hepatogastroenterology 2002; 49: 1113-5.

23. Fritscher-Ravens A, et al. EUS-guided fine-needle aspiration of suspected hilar cholangiocarcinoma in potentially operable patients with negative brush cytology. Am J Gastroenterol 2004; 99: 45-51. 
24. Jacobson BC, Pitman MB, Brugge WR. EUS-guided fine-needle aspiration for the diagnosis of gallbladder masses. Gastrointest Endosc 2003; 57: 251-4

25. Sailer M, Buseen D, Fein M, Freys S, Debus SE, Thiede A, et al. Endoscopic ultrasound-guided transrectal biopsies of pelvic tumors. J Gastrointest Surg 2002; 6: 342-6.

26. Gupta RK, Cheung YK, alAnsari AG, Naran S, Lallu S, Fauck R. Value of image-guided needle aspiration cytology in the assessment of pelvic and retroperitoneal masses. A study of 112 cases. Acta Cytol 2003; 47: 393-8.

27. Ginés A, Vázquez-Sequeiros E, Soria MT, Clain JE, Wiersema MJ. Usefulness of EUS-guided fine-needle aspiration in the diagnosis of functioning neuroendocrine tumors. Gastrointest Endosc 2002; 56: 291-6.

28. Prasad P, et al. Detection of occult liver metastases during EUS for staging of malignancies. Gastrointest Endosc 2004; 59: 49-53.

29. Lai R, Stephens V, Bardales R. Diagnosis and staging of hepatocellular carcinoma by EUS-FNAof a portal vein thrombus. Gastrointest Endosc 2004; 59: 574-7.

30. Hollerbach S, Willert J, Topalidis T, Reiser M, Schmiegel W. Endoscopic ultrasound-guided fine-needle aspiration biopsy of liver le- sions: histological and cytological assessment. Endoscopy 2003; 35 : 743-9.

31. Wildi SM, et al. Endoscopic ultrasonography in the diagnosis and staging of neoplasms of the head and neck. Endoscopy 2004; 36: 62430 .

32. Súbtil Iñigo JC, Fernández-Urién I, Muñoz Navas M. Ultrasonografía endoscópica intervensionista: diagnóstica y terapéutica. En: Souto Ruzo J, ed. Ultrasonografía endoscópica. Tomo II. Barcelona: Editorial Glosa, 2002.

33. Gress F, Schmitt C, Sherman S, Ikenberry S, Lehman G. A prospective randomized comparison of endoscopic ultrasound- and computed tomography-guided celiac plexus block for managing chronic pancreatitis pain. Am J Gastroenterol 1999; 94: 900-5.

34. Gunaratnam NT, Sarma AV, Norton ID, Wiersema MJ. A prospective sudy of EUS-guided celiac plexus neurolysis for pancreatic cancer pain. Gastrointest Endosc 2001; 54: 316-24.

35. Gress F, Schmitt C, Sherman S, Ciaccia D, Ikenberry S, Lehman G. Endoscopic ultrasound-guided celiac plexus block for managing abdominal pain associated with chronic pancreatitis: a prospective single center experience. Am J Gastroenterol 2001; 96: 409-16. 